\title{
CORRESPONDENCE.
}

\section{ILLUMINATION OF SNELLEN'S DISTANT TEST TYPES}

\section{To the Editor of The BRITISH Journal of OpHTHALMOLOGY.}

SIR,-I read in the January number of THE BRITISH JOURNAL OF Ophthalmology that the Council of British Ophthalmologists has issued directions for the illumination of test types in estimating visual acuity.

With the prescribed amount of illumination the test becomes purely one of definition, and as this is the case it seems a pity that one of the obvious defects of most existing sheets of test types was not guarded against at the same time.

Perfect definition implies that all points of the letter be brought to a focus in the retinal image; the greater the departure from this condition, the wider become the confusion circles, and the bigger the blur on the edges of the retinal image. The critical factor in the test of definition is the extent to which the confusion circles reach across the intervals which separate the limbs of the letters; with a slight blur the letters may still be distinguished, it is only when the blurred edges of the limbs overlap that the letter becomes indistinguishable. It is obvious that no two parts of the letter should be wider apart than the unit interval which is proper to each grade of letter. There are certain letters, such as O, C, D, L, which cannot be designed in conformity with this condition. These letters should be omitted, as also should such letters as A and V, whose shape betrays their identity even when they are blurred.

I wish to suggest that in a scheme for a universally comparable test this condition should be considered.

$$
\text { I am, Sir, yours faithfully, }
$$

3, New Bond Street, W.

W. A. DiXey.

\section{NOTES}

WE regret to announce the recent deaths of Deaths two distinguished physicians who were members of the Ophthalmological Society of the United Kingdom, namely, Thomas Buzzard, aged 87 years, and Leonard G. Guthrie, aged 60 years.

The former was an original member of the Society, in which he had held the offices of councillor (1881-2) and vice-president (1888-91). When he resigned his membership some few years 